\title{
Differences and geological significance of vitrinite and exinite in source rocks from the KQT area of Xihu Sag, eastern China
}

\author{
Min Xu ${ }^{1}$, DujIe Hou ${ }^{1}$, Xiong Cheng ${ }^{1}$, Jinshui LiU ${ }^{2}$, \\ HUi DiaO ${ }^{2}$ \\ ${ }^{1}$ China University of Geosciences, Beijing 100083, China \\ ${ }^{2}$ Shanghai Branch of CNOOC, Shanghai 200050, China
}

The Xihu Sag is located in the East China Sea Shelf Basin on the continental margin of eastern China, which is an important prospective area for petroleum exploration, especially for gas and condensate. The KQT is located in the north of Pinghu tectonic belt on the western slope of Xihu sag, whose source rocks (SRs) are predominantly coal-bearing SRs of Huagang and Pinghu Formation, of which the type of Organic matter is II-III, concentrated in type $\mathrm{II}_{2}$, likewise, they are also the main reservoirs. Delta-tidal flat depositional system was developed in Pinghu Formation as a whole, while Huagang Formation was dominated by the delta plain.

Remarkably, there are significant differences in the contents of vitrinite and exinite in maceral composition of SRs from KQT. A total of 65 samples from 9 wells in KQT, among which 27 samples showed higher content of exinite than that of vitrinite, while vitrinite dominated the rest 38 samples. On the plane, the content of exinite tends to increase from west to east, which is consistent with the source direction. According to previous research, the results of the simulation of hydrocarbon generation indicate that the hydrocarbon generation products of the SRs dominated by vitrinite are mainly gaseous hydrocarbons, while the exinitedominated SRs tend to produce liquid hydrocarbons[1]. In KQT area, wells whose SRs with high vitrinite, such as NB13-4-1 and KQT 1, chiefly produce natural gas, while condensate is the primary product of the exinite-dominated SRs, such as in NB14-5-3. Above facts verify the conclusion of hydrocarbon-generation simulation to some extent.

On East China coastal area, gymnosperms and angiosperms, rich in resinite and sporinite, which all are the main components of the exinite, coexisted in the Tertiary. The resinite with higher stability had a relatively longer migration distance than vitrinite by river transportation. Therefore, with the increasing distance from the source, the vitrinite predominance gradually disappears, while the exinite content increases accordingly. The relative changes can predict the trend of paleochannel, which is beneficial to reconstruct the paleoenvironment.

[1] Menhui Qian et al.(2012) Petroleum geology\&experiment 34,182-185. 